\title{
Ferritin level may be a major factor in young females with recurrent aphthous stomatitis
}

\author{
Najla Dar-Odeh ${ }^{a, b}$ and Osama Abu-Hamamda,b
}

\author{
${ }^{a}$ College of Dentistry, Taibah University, Al Madinah Al Munawara, Saudi Arabia. \\ 'SSchool of Dentistry, University of Jordan, Amman, Jordan. \\ Correspondence to Najla Dar-Odeh (email: najla_dar_odeh@yahoo.com). \\ (Submitted: 14 April 2019 - Revised version received: 03 July 2019 - Accepted: 13 August 2019 - Published online: 26 October 2019)
}

Recurrent aphthous stomatitis is considered the most common type of recurrent oral ulcers that affects adversely the quality of life of patients. Its etiology is not well understood; however, nutritional and psychosocial factors have been suggested in a certain category of patients. The aim of this case series is to describe the hematological picture namely hemoglobin level, serum vitamin B12 and serum ferritin in six young female patients affected by recurrent aphthous stomatitis, and to report its association of low serum ferritin.

Keywords ferritin, aphthous stomatitis, young, females

\section{Introduction}

Recurrent aphthous stomatitis (RAS) is considered the most common type of recurrent oral ulcers. Clinically these ulcers present in three forms; the minor, major and herpetiform ulcers. The most common form of these is the minor type which affects more than $85 \%$ of RAS patients. ${ }^{1}$ Minor ulcers appear as shallow ulcers with a yellowish-whitish floor and a well-defined red halo that is regular in shape. Occurrence and recurrence of RAS will eventually affect the quality of life of patients due to the associated oral soreness and burning sensation jeopardizing oral functions like speaking and mastication.

Approximately $20 \%$ of the general population is affected by RAS, but incidence varies from $5 \%$ to $50 \%$ according to ethnicity and socioeconomic status. ${ }^{2}$ Although etiology of RAS is not well-determined yet, nutritional and psychosocial factors have been suggested in a certain category of patients. ${ }^{3}$ A small percentage of RAS patients (5-10\%) show low serum levels of iron, folate, zinc, or vitamins B1, B2, B6 and B12 indicating that nutritional deficiency is apparently an etiological factor for RAS. ${ }^{3}$

This case series aims to report the laboratory findings namely hemoglobin level, serum vitamin B12 and serum ferritin in seven RAS patients who attended the oral medicine clinic at Taibah University Dental Hospital (TUDH) for treatment of their oral ulcers. It also aims to report the low serum ferritin level that was observed in these patients. This report is part of a larger project that was initiated at TUDH/Female Section to investigate oral diseases among female patients. Ethical approval was obtained from Taibah University, College of Dentistry Research Ethics Committee-ethical approval \#TUCDREC/20171213/Dar-Odeh.

\section{Case Series}

Patients attended the oral medicine clinic complaining of recurrent oral ulcers. All patients reported no medical illness except for the oral ulcers. They had minor ulcers that appeared exclusively in the labial and/or buccal mucosa (Figs. 1 and 2).

History and clinical features were suggestive of RAS. Topical treatment based on hyaluronic acid was prescribed to patients and they were referred to the same laboratory to perform the following tests: complete blood count, serum ferritin and serum vitamin B12. Patients' age range was 13-34 years (mean $=20.4, \mathrm{SD}=6.9$ ). Only one patient was anemic [hemoglobin $(\mathrm{Hb})=9.2 \mathrm{~g} / \mathrm{dl}$ ], while the rest of patients had a normal $\mathrm{Hb}$ level $($ mean $=13, \mathrm{SD}=1.74)$. Serum ferritin level ranged from 6 to $50.8 \mathrm{ng} / \mathrm{ml}($ mean $=26.1, \mathrm{SD}=15.2)$, and serum vitamin B12 ranged from 164 to $764 \mathrm{pg} / \mathrm{ml}($ mean = 461.4 , SD $=226.7$ ). Patients who had low serum ferritin were prescribed iron supplements, and they showed marked improvement in symptoms following therapy.

\section{Discussion}

The report describes hematological findings in a series of young female patients who attended the oral medicine clinic or TUDH. Six RAS patients had low serum ferritin level.

There are a number of factors that need to be approached when addressing RAS in young female patients, namely; serum ferritin levels, anemia, and stress initiated by school life. Iron deficiency is considered the most common nutritional deficiency, ${ }^{4}$ with women at a higher predisposition to developing iron deficiency, ${ }^{4}$ and to become anemic. Possible causes for iron deficiency in our patients may include reduced intake and/or increased loss through menstruation. In women, appearance of RAS may coincide with menses, and studying-related stress may further explain the higher prevalence of RAS in students. ${ }^{5}$ Previous studies have pointed out to the poor oral health of young women in this geographic area manifested as jaw pathology in the form of remaining roots and periapical (tooth-related) bone lesions. ${ }^{6,7}$ This poor level of oral health is expected to adversely affect oral functions like mastication with resultant reduced consumption of healthy diet.

Anemia in women is defined by the World Health Organization as an $\mathrm{Hb}$ level that is below $12.0 \mathrm{~g} / \mathrm{dl},{ }^{8}$ hence, only one of the patients had anemia ( $\mathrm{Hb}$ level $<12.0 \mathrm{~g} / \mathrm{dl}$ ). Iron deficiency, on the other hand, is best evaluated by measuring serum ferritin levels. ${ }^{9}$ This may explain why RAS is more prevalent among women.

Taking into consideration the fact that ferritin is an acute phase protein that can be elevated in a variety of inflammatory 


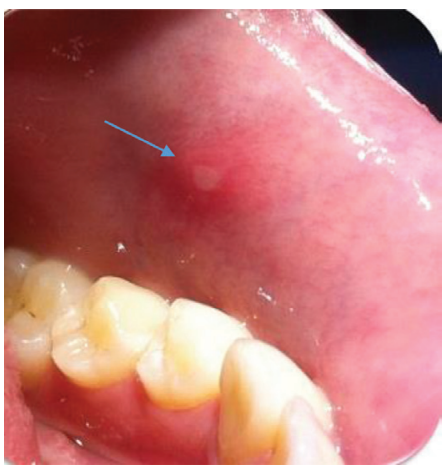

Fig. 1 Minor aphthous ulcer (arrow) affecting the labial mucosa of a non-anemic 22-year-old woman with a serum ferritin level of $11.9 \mathrm{ng} / \mathrm{ml}$.

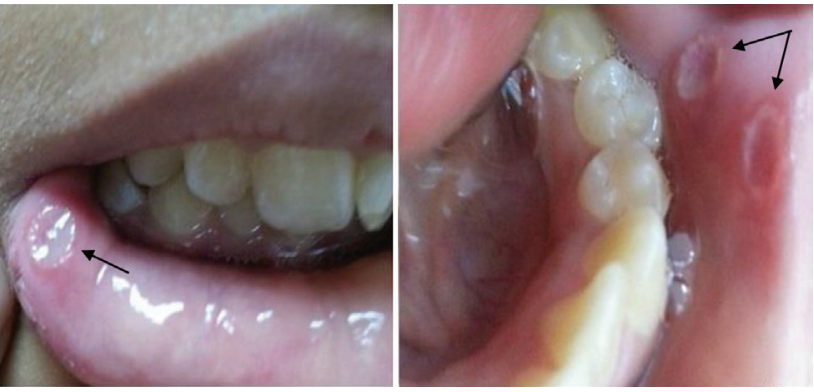

Fig. 2 Minor aphthous ulcers affecting the labial mucosa in a 13-year-old girl.

and infectious conditions, individuals may still have normal ferritin levels in spite of being iron deficient (false negatives).
Serum ferritin level was found to have no association with certain infections of the oral mucosa like candidiasis in young females; ${ }^{10}$ however, it is critical for the growth and differentiation of all cells, and its deficiency may lead to epithelial abnormality or atrophy. ${ }^{11}$ Many studies have reported a highly significant reduction in the total epithelial thickness, particularly the thickness of the maturation compartment. ${ }^{12}$

Iron deficiency without overt anemia can result in neuropsychological effects and it has been linked to delayed cognitive development in children and adolescents. ${ }^{13}$ Interestingly, the diagnosis of nutritional deficiency and anemia from oral mucosa changes can be established in the absence of symptomatic anemia or even in the pre-anemic stage. ${ }^{14}$

Patients who are not anemic but have serum ferritin levels of $<15-30 \mathrm{ng} / \mathrm{ml}$ are diagnosed as having tissue iron deficiency. ${ }^{15}$ Six out of seven of our patients had serum ferritin levels of $\leq 30 \mathrm{ng} / \mathrm{ml}$ indicating tissue iron deficiency. It had been suggested that hematologic screening of RAS patients for anemia or deficiency of iron, folate, and B vitamins is appropriate for patients with major RAS or cases of minor RAS that worsen during adult life. ${ }^{1}$ According to the findings of this case series, another category of RAS patients that require hematologic screening may also include young females.

Routine hematological screening for serum ferritin, folic acid and vitamin B12 should be assessed in all patients with RAS, particularly young females, to treat any nutritional deficiency and to prevent more important related systemic manifestations.

\section{Conflicts of Interest}

The authors declare that they have no conflicts of interest.

\section{References}

1. Akintoye SO, Greenberg MS. Recurrent aphthous stomatitis. Dent Clin North Am. 2005;49:31-47.

2. Rogers RS. Recurrent aphthous stomatitis: clinical characteristics and associated systemic disorders. Semin Cutan Med Surg. 1997;16:278-283.

3. Dar-Odeh NS, Alsmadi OM, Bakri F, Abu-Hammour Z, Shehabi AA, Al-Omiri MK, et al. Predicting recurrent aphthous ulceration using genetic algorithmsoptimized neural networks. Adv Appl Bioinforma Chem. 2010;3:7-13.

4. Lu SY. Perception of iron deficiency from oral mucosa alterations that show a high prevalence of Candida infection. J Formos Med Assoc. 2016;115:619-627.

5. McCann AL, Bonci L. Maintaining women's oral health. Dent Clin North Am. 2001;45:571-601

6. El Khateeb SM, Abu-Hammad O, Fadel H, Dar-Odeh N. A retrospective analysis of radiographic jaw findings in young women; prevalence and predictors. J Int Soc Prev Community Dent. 2017;7:22-27.

7. Dar-Odeh NS, Aleithan FA, Alnazzawi AA, Al-Shayyab MH, Abu-Hammad SO, Abu-Hammad OA. Factors affecting oral health determinants in female university students: a cross-sectional survey in Saudi Arabia. Int J Adolesc Med Health. 2017.

8. Cappellini MD, Motta I. Anemia in clinical practice-definition and classification: does hemoglobin change with aging? Semin Hematol. 2015:52:261-269.

9. Guyatt GH, Oxman AD, Ali M, Willan A, Mcllroy W, Patterson C. Laboratory diagnosis of iron-deficiency anemia - An overview. J Gen Intern Med. 1992:7:145-153.

10. Dar-Odeh NS, Shehabi A, Al-Bitar ZB, Al-Omari IK. Oral Candida colonization in patients with fixed orthodontic appliances: the importance of some nutritional and salivary factors. Afr J Microbiol Res. 2011:5:2150-2154.

11. Bermejo F, García-López S. A guide to diagnosis of iron deficiency and iron deficiency anemia in digestive diseases. World J Gastroenterol. 2009;15:4638-4643.

12. Wu YC, Wang YP, Chang JY, Cheng SJ, Chen HM, Sun A. Oral manifestations and blood profile in patients with iron deficiency anemia. J Formos Med Assoc. 2014;113:83-87.

13. Grantham-McGregor S, Ani C. A review of studies on the effect of iron deficiency on cognitive development in children. J Nutr. 2001:131:649S-666S; discussion 666S-668S

14. Lu SY, Wu HC. Initial diagnosis of anemia from sore mouth and improved classification of anemias by MCV and RDW in 30 patients. Oral Surg Oral Med Oral Pathol Oral Radiol Endod. 2004;98:679-685.

15. Pasricha SRS, Flecknoe-Brown SC, Allen KJ, Gibson PR, McMahon LP, Olynyk JK, et al. Diagnosis and management of iron deficiency anaemia: a clinical update. Med J Aust. 2010;193:525-532. 